América sin Nombre, n.o 23 (2018): 123-132

DOI 10.14198/AMESN.2018.23.09

ISSN: 1577.3442 / eISSN: 1989-9831

Fecha de recepción: 05/06/2018

Fecha de aceptación: 04/07/2018
Modo de citación de este artículo:

Ramírez Cruz, Israel. «Reconfiguración del campo poético en México. 2001 y 2016: un mínimo acercamiento a partir de dos revistas». Madurez de la joven poesía mexicana. Alejandro Higashi e Ignacio Ballester (coordinadores). América sin Nombre, 23 (2018): 123-132, DOI: 10.14198/ AMESN.2018.23.09

Link para este artículo: http://dx.doi.org/10.14198/AMESN.2018.23.09

\title{
Reconfiguración del campo poético en México. 2001 y 2016: un mínimo acercamiento a partir de dos revistas
}

\author{
Reconfiguration of the poetic field in Mexico. 2001 and 2016: \\ a minimum approach from two journals
}

\author{
Israel Ramírez Cruz* \\ El Colegio de San Luis (México)
}

\begin{abstract}
Resumen
El artículo tiene por objetivo poner en contraste la poesía publicada en dos momentos específicos de la historia literaria mexicana: la del año 2001 y la del 2016. El trabajo propone la revisión de los poemas que aparecieron en dos revistas de distribución nacional y de amplio reconocimiento en el medio. De igual forma, parte de una visión que busca integrar este periodo poético de principios del siglo XXI a un proceso mayor que se extiende, en principio, hasta la década de 1990; con ello, se justifica la elección de Nexos y Letras Libres como corpus de estudio, así como se establece un contexto común para las revistas y los poemas que aparecieron en sus páginas. Entre los hallazgos de la investigación destaca que en una se privilegió la poesía de tendencia coloquial, mientras que en la otra domina una poesía de corte intimista que parte del yo. Estos dos modelos se suman a una amplia diversidad de tendencias que exhiben los discursos poéticos recientes en México, pero también se comprueba la ausencia de propuestas experimentales o de ruptura en sus páginas, así como el poco número de mujeres o de poesía escrita en lengua indígena en sus índices.
\end{abstract}

Palabras clave: revistas literarias, poesía mexicana, Nexos, Letras Libres

\section{Abstract}

The article aims to contrast the poetry published in two specific moments of Mexican literary history: the year of 2001 and the year 2016. The work proposes the revision of the poems that appeared in two magazines of national distribution and wide recognition in the middle. Likewise, part of a vision that seeks to integrate this poetic period of the beginning of the 21 st century into a larger process that extends, in principle, until the 1990s; with it, the choice of Nexos and Letras Libres is justified as a corpus of study, as well as establishing a common context for the magazines and poems that appeared on its pages. Among the findings of the research highlights that in one poetry was privileged colloquial trend, while in the other dominates an intimate court poetry part of the self. These two models are added to a wide diversity of

* https://orcid.org/0000-0001-8283-4946

Doctor en Letras Mexicanas por la UNAM, actualmente se desempeńa como profesor-investigador de El Colegio de San Luis, coordinador del Fondo bibliográfico Ramón López Velarde y director de la Revista de El Colegio de San Luis. Su trabajo se orienta a la investigación de literatura mexicana y poesía hispanoamericana, así como a la historiografía literaria y los estudios de edición crítica genética de obras contemporáneas. En 2009 fundó el Seminario de Investigación en Poesía Mexicana Contemporánea. 
tendencies exhibited by the recent poetic discourses in Mexico, but there is also evidence of the absence of experimental or rupture proposals in their pages, as well as the small number of women or poetry written in the indigenous language in their indexes.

Keywords: Mexican poetry, Literary magazines, Letras Libres, Nexos

Dentro de toda su arbitrariedad, la periodización en los trabajos de revisión histórica permite fijar al menos un par de condiciones de lectura. En principio, aclara muy bien la postura del crítico que enmarcó -dentro de tales coordenadas temporalesla serie de hechos (y efectos) que quiere poner a dialogar entre sí; es decir, revela el tipo de discusión que se pretende, pues pone de relieve los matices políticos, económicos o culturales con los que identifica dichas fechas. En segundo lugar, contribuye al entendimiento del continuum por medio de un acercamiento que delimita en su corte un punto de quiebre -una diferencia frente a las condiciones que le anteceden- bajo la hipótesis de que esta temporalidad merece ser estudiada como parte de un proceso mayor, puesto que su examen aporta información que de otro modo no sería fácil de entender.

En este caso, las variables que se destacan en el acercamiento a estos 15 ańos de escritura poética en México parten del comentario a dos revistas centrales dentro del contexto cultural del país: Letras Libres y Nexos ${ }^{1}$, de lo que ahí se publicó y de lo que representan tales espacios (en su carácter hegemónico y en su contraposición a los medios marginales). Además, permítase un alegato -para aludir a Ramón López Velarde- que aclare que estas notas le deben mucho al olfato, pero carecen aún de todo el desarrollo metodológico y de la investigación que merece este periodo tan complejo.

1. Son variados y de diverso alcance los trabajos sobre revistas culturales, mismos que van de Beatriz Sarlo y Mabel Moraña hasta Rafael Ozuna, así como las referencias que se pueden consignar sobre Letras Libres y Nexos, en particular. Se recomienda, de entre el conjunto, el libro de Malva Flores, Viaje de Vuelta. Estampas de una revista, y el de Jaime Perales, Octavio Paz y el círculo de la revista Vuelta; así como los números del décimo, vigésimo, trigésimo y cuadragésimo aniversario de Nexos, donde se da cuenta del origen y sucesivos cambios que ha tenido esa publicación a lo largo de su vida.

\section{Contexto}

A los planteamientos articulados por Ana Pizarro sobre la historia de la literatura latinoamericana, en los que se problematiza en torno a la periodización, los espacios/regiones en los que se agrupan las producciones literarias y el cambio que el estatuto de lo literario evidencia hacia mediados del siglo $\mathrm{xx}$, se añade que el proceso de revisión, construcción o reconstrucción de la historia literaria también se ve afectado por el giro lingüístico, es decir, por la aceptación de que la historia se construye como discurso. Bajo este antecedente, fuentes, intuiciones, presuposiciones y conjeturas son presentadas aquí no como exposición científica de resultados, sino como hipótesis de una discusión mayor.

Al regresar al punto de partida de estas notas, lo primero que hay que discutir es el corte temporal. En este sentido, es posible especificar que tres lustros son en principio el pretexto que agrupa (en una cifra cerrada) los años que han pasado desde el cambio de siglo. Ahora bien, como material de estudio, estos primeros quince años del siglo xxi consolidan un proceso que había iniciado desde finales de la centuria pasada en el marco de la crisis económica y política de 1994, del asesinato del candidato presidencial Luis Donaldo Colosio, la salida de Carlos Salinas de Gortari de la Presidencia y la llegada de Ernesto Zedillo, el ingreso al Tratado de Libre Comercio de América del Norte (TLCAN), así como del levantamiento del Ejército Zapatista de Liberación Nacional (EZLN), la emergencia de nuevas promociones literarias y la disolución de una manera de concebir la literatura; en el contexto internacional, la globalización incide en la recomposición de los sellos editoriales y su agrupación en grandes trasnacionales que distribuyen las obras - no todas, claroen mercados más grandes (un ejemplo puede ser la compra de Joaquín Mortiz por Editorial Planeta) ${ }^{2}$.

2. Justo es decir que para lo que atańe a la poesía, los grandes sellos y sus fusiones multimillonarias poco inciden en el mercado en que se publica y vende la poesía en México, si se enfocan las prácticas de distribución que siguieron: Aldus, Cal y 
Destaca también el mayor contacto entre poetas, gestores culturales y revistas de diferentes países, la difusión de blogs y sitios personales que permiten la autopublicación y circulación de los contenidos sin intermediarios, entre otros muchos elementos que en la década de 1980 eran impensables.

Atrás quedan las lecciones del encuentro La experiencia de la libertad, organizado por Vuelta en 1990, y del Coloquio de invierno, planeado por Nexos dos años después. Mucho más lejos están los constantes referentes que se han tenido para articular la historia de la poesía mexicana en su etapa contemporánea, por ejemplo Poesía en movimiento o la Asamblea de poetas jóvenes de México (aunque no por ello se da la espalda a lo que Anthony Stanton llama «formulación del canon» (21-60) al referirse al papel de tres importantes antologías en el campo literario mexicano). Lejos, porque no ha desaparecido el empuje de aquellos 164 jóvenes autores que Zaid reunió en la Asamblea..., muchos de ellos editores en revistas, encargados de sellos editoriales, profesores universitarios, talleristas, directivos en instituciones culturales, traductores, autores galardonados en premios de poesía ${ }^{3}$.

No hay procesos únicos, ni procesos puros. Los quince ańos que se estudian aquí, se intersectan con lo que está en el aire: lo mismo la emergencia de Ulises Carrión y de Gerardo Deniz, que la coronación de la trayectoria de José Emilio Pacheco o la

Arena, Ediciones Sin Nombre, El Equilibrista, El Ermitaño, Praxis, Premiá, El Tucán de Virginia, Universidad Autónoma Metropolitana, Universidad Nacional Autónoma de México y Verdehalago, por mencionar sólo algunos sellos que jugaron un papel decisivo en este periodo.

3. Entre los poetas reunidos por Zaid se encuentran: Alberto Blanco, Coral Bracho, Carmen Boullosa, Héctor Carreto, Ricardo Castillo, José María Espinasa, Kyra Galván, Eduardo Hurtado, Eduardo Langagne, Mara Larrosa, Víctor Manuel Mendiola, Fabio Morábito, Vicente Quirarte, José de Jesús Sampedro, Javier Sicilia, Marcelo Uribe, Frida Varinia Ramos y Verónica Volkow, por mencionar sólo algunos. Esta Asamblea congrega a muchos de los autores nacidos en la década de 1950, cuyas obras integran el punto de quiebre a partir del cual la poesía mexicana instaura un periodo claramente distinto dentro de la historia literaria nacional. Los años que corren de finales de 1960 y hasta finales del siglo xx y principios del siglo xxi pueden ser comprendidos a la luz de preocupaciones semejantes; cosa que no sucede con los años posteriores, en los que las nuevas promociones poco a poco insertan en los modelos de escritura nuevos planteamientos temáticos y actitudes distintas frente al fenómeno de la literatura, su discusión y lectura. aparición de nuevas editoriales. ¿Cómo acercarse a este periodo si el fenómeno incluye muchas variantes? En principio, es posible trabajar con materiales aceptados por todos: ¿los premios de poesía? Podrían ser entonces los Premios Aguascalientes de estos 15 años a los que ya se ha aludido. Sin embargo, es igual de válido -y limitado- analizar los libros ganadores de los premios de poesía que se convocaron en este periodo en territorio nacional si lo que se pretende es comprender un espectro amplio en su devenir histórico. Los ganadores del Aguascalientes, del Elías Nandino, del Owen, del Ramón López Velarde, del Acuña, del Punto de Partida, del Clemencia Isaura, entre otros.

Pese a lo anterior, todos esos poemarios ganadores, todos juntos, tampoco dan cuenta de lo acontecido en el campo poético de estos años. Proceder de este modo en los trabajos de historia es repetir el paradigma de que los vencidos no forman parte del relato. Lo que se ha hecho al repetir estudios sobre los premiados, los becados, los publicados, es contribuir al oscurecimiento de una zona inmensa de nuestras letras. Si para el Premio Aguascalientes concursaron, tan sólo en 2008 (año en que lo declararon desierto Jorge Esquinca, José Javier Villarreal y José Luis Rivas) 207 manuscritos, estudiar 15 libros ganadores del Premio Aguascalientes se traduce en dejar de leer la friolera de 3090 libros. Visto así, el afán totalizador de la bibliografía se relativiza.

Es por ello que en este trabajo se opta por el análisis de materiales más convencionales, asumiendo que al lado suyo hay un corpus inmenso que se queda rezagado. Se trata de dos publicaciones de fácil acceso, de amplio tiraje, de público muy claramente formado y de incidencia semejante en el medio: Letras Libres y Nexos ${ }^{4}$.

\section{Mínimo acercamiento}

A pesar de sus fechas de aparición (una en 1978 y la otra en 1999), la historia las emparienta. Letras Libres se desprende del proyecto que arranca con Vuelta (1976-1998), misma que tiene su antecedente en Plural (1971-1976). Ambos proyectos están ligadas a un momento particular de la historia mexicana:

4. Este acercamiento se limita a las publicaciones impresas, puesto que ambas mantienen sitios electrónicos cuyo contenido no es idéntico al que aparece en papel. 
Plural, fundada por Octavio Paz en 1971, marcará el inicio de una etapa caracterizada por el protagonismo de unas cuantas publicaciones periódicas que acapararán el panorama crítico hasta hoy en día. Vuelta, fundada en 1976 y dirigida desde entonces por el mismo Paz, y Nexos, fundada en 1978 por Enrique Florescano, pero dirigida desde 1982 por Héctor Aguilar Camín, se convertirán en los dos polos en torno a los cuales gira la cultura mexicana contemporánea. Polarización que implica además un posicionamiento ideológico, como ya se había observado en otros momentos de la historia cultural reciente... (Vidal López-Tormos 265).

Para 2001, aunque una inicie su tercer aniversario y la otra tenga cumplidos los 22 ańos, el recién inaugurado siglo XXI les exigía cubrir retos semejantes: una mayor representación de la realidad y la diversidad ideológica y artística que flotaba en el ambiente. Si Nexos se orientó hacia el análisis político, histórico y económico, Letras Libres continuó una tendencia semejante a Vuelta, por lo cual le otorgó un espacio constante a las manifestaciones literarias. Estas son algunas de las razones que llevan a examinarlas a la par, pero que también impiden una ciega comparación que no respete la distancia que las separa.

En afán de la precisión, no se analizarán en su papel de revistas hegemónicas en el campo literario mexicano, sino la poesía que se publica en sus páginas y cómo ésta da indicios de continuidad o ruptura dentro del mismo medio. Se parte del presupuesto de que si esta poesía se publica, más allá de los grupos o las tendencias que se identifican en cada medio, es porque existen más autores que también comparten estos presupuestos estéticos; de igual manera, se asume que las diferencias ideológicas entre ambas revistas no afectan a su plan de publicar textos literarios y poesía de manera más o menos frecuente.

En 1999, en el primer número de Letras Libres, Enrique Krauze escribió en la «Presentación» las siguientes palabras: "Aunque publicaremos a los destacados autores que concurrieron en sus páginas [se refiere a Plural y Vuelta], en Letras Libres -nombre acuñado por el propio Paz- no nos sentimos herederos automáticos de su legado: haremos lo posible por conquistarlo» (Krauze 6).

Si se revisan las páginas de su tercer año, se comprueba que Krauze y la nómina de sus colaboradores entendían esa herencia sin reservas, de ahí que en 2001 aparecieran poemas de David Huerta, Eduardo Hurtado, un «Recuento» de Octavio Paz en la pluma de Gabriel Zaid, notas de Francisco Cervantes, reseñas sobre Gloria Gervitz, Alfonso D’Aquino y Eduardo Hurtado, poesía de Daniel Sada, "traducciones» de haikús de José Emilio Pacheco, textos de José Luis Rivas, María Baranda, Jorge Hernández Campos, sonetos de Tomás Segovia (como los de Eliseo Diego en Nexos), poemas de Ernesto Lumbreras, Jorge Esquinca, Ramón Xirau, Luis Vicente de Aguinaga y notas sobre Muerte sin fin de Julio Trujillo y de Tedi López Mills sobre Eliot.

Por su parte, en su primer número, enero de 1978, Nexos declaraba que:

quiere ser en lo fundamental lo que su nombre anuncia: lugar de cruces y vinculaciones [...]. Es, sobre todo, un intento de exhibir y volver accesibles los conocimientos y recursos intelectuales de que disponemos para entender los problemas estratégicos de México. Se presenta a sus lectores como el esfuerzo mancomunado de muchas voluntades dispuestas a la comunicación recíproca, al diálogo razonado y a la búsqueda de alternativas fundadas en la reflexión. Nace con la certidumbre de que los estudiosos de la naturaleza y de la sociedad, así como los creadores de la literatura y las artes, deben unir sus esfuerzos y colaborar en el análisis exigente y amplio de los problemas pasados y presentes de nuestra sociedad [palabras que han sido citadas en los números de aniversario por sus 10 y 20 ańos] (ctd. del «Editorial» publicado en 1992: 10).

Para el mismo año de 2001, Nexos publicó doce sonetos de Eliseo Diego, una nota de Jennifer Clement sobre la poesía cowboy (que a continuación se cita), la traducción al español -a cargo de Luis Miguel Aguilar- de un texto de W. D. Snoodgrass y un poema de Vicente Quirarte pensado bajo el espíritu de Gilberto Owen.

A finales del mes de enero de los últimos 17 años, ganaderos, labriegos, poetas, músicos, talabarteros y devotos del oeste se han reunido en Elko, Nevada, durante una semana de diálogo cowboy, de cantos y bailes, de botas y enormes sombreros, de anécdotas y mucha carne asada, de pláticas sobre la cultura estanciera, la tradición vaquera y, en especial, sobre la poesía. Ocho mil personas acudieron el año pasado. Quien quiera puede asistir a este encuentro; no obstante, si alguien desea participar como poeta deberá demostrar, antes de proponer sus versos y en presencia de un comité de selección, que es un «verdadero cowboy». Lo cual significa que es más importante saber 
montar a caballo o jugar una partida de pókar, que escribir un soneto (Clement 81).

Para 2001, tal como lo apunta la nota de Clement, la poesía está entre el rodeo y las páginas de una revista hegemónica. Así como en Nexos, Letras Libres presenta el mismo tono "Contra el sopor», de Julio Trujillo. Breve nota sobre las lecturas de poesía donde refiere que:

Poesía sonora, poesía acción, poesía slam son términos con los que no estamos muy familiarizados. Pero en Londres, París o Chicago se usan y ponen en práctica desde hace décadas. Se trata de sacar la poesía de los libros y presentarla de manera activa, entretenida, ágil, en lecturas o performances frente a un público participativo y numeroso [para concluir que:] En poesía no hay que hablar de usted jamás. Traslademos nuestros ruidosas tertulias y convivios (con todo y sus aderezos musicales y sus paraísos artificiales) a sus foros escépticos y vacíos antes de que matemos de aburrición incluso a nuestras mamás (Trujillo 101).

Los cambios que se suceden entre el año 2001 y 2016 corresponden al arco que corre -en sus extremos-a la poesía escrita por los nacidos a mediados de la década de 1970 y los nacidos en la década 1990 (esto si consideramos que los poetas publican sus poemas en revistas a partir de los 25 ańos); por supuesto -aclaro, como apuntamos atrás-, no sólo publican las nuevas promociones, sino autores de larga trayectoria. De los poetas publicados en 2001 en Letras Libres, el menor tiene 30 años (Luis Vicente de Aguinaga) y el de mayor edad cuenta con 80 (Jorge Hernández Campos). Nexos, por su parte, sólo presenta a un poeta de 47 años: Vicente Quirarte.

Los demás, que son el infierno, añaden a tu rostro una capa de rememoraciones.

La diluyen también

o la retiran, agravándola:

polvo que reducido a polvo

se acumula (de Aguinaga 48).

De Quirarte cito unas líneas del arranque de «Sin convite a tu fiesta de fantasmas»:

La mañana de mayo en que te fuiste

era el viento un tenaz enamorado

embriagado en las copas

de árboles que crecieron con nosotros.

$[\ldots]$
Hoy esos tornillos se me oxidan en clavos

y este nuevo caballo de tequila

no electriza mi sangre

ni me monta en la yegua de otros días (Quirarte 18).

En ambos autores hay un deseo de perfección formal que atraviesa la concepción más clásica de la poesía: armonía, profundidad en el tema y su abordaje, brevedad y concreción. Se nota además una tensión entre el isosilabismo y su abolición (aunque no de la repetición y el remate contundente al final de las secciones o del poema); mientras que en Quirarte dominan los endecasílabos, Luis Vicente de Aguinaga se aleja del metro para construir la musicalidad en la alternancia de un registro epigramático, la repetición léxica y el acento en la tercera sílaba que aparece en el primero, segundo y quinto verso. En uno, la contundencia que exige el fragmento y, en el otro, la de un intimismo que explota con elegancia el registro coloquial arropado en versos bien templados.

Los casos de mayor disrupción en Nexos son el poema de Barney Nelson que cita Jennifer Clement ( «La poesía es cuero. / Poesía es cuando los caballos / corcovean sin ningún / motivo y no cuando debieran hacerlo») y el de Luis Miguel Aguilar, "A la Borges: poema de las imposibles recomendaciones», escrito a partir de «casos recibidos por la Comisión de Derechos Humanos del Distrito Federal bajo la gestión de Luis de la Barreda Solórzano", mismo que se conecta tangencialmente con lo que Jaime Reyes había hecho en La oración del ogro (1984) al rescatar las entrevistas de campesinos y habitantes de la ciudad entre 1979 y 1982 que aparecieron en el periódico o que se hicieron para el Instituto Nacional Indigenista. He aquí una muestra de Luis Miguel Aguilar:

He sido la mujer que sabe de sus agresores, aunque no pueda precisarlos - tal es el trabajo de otros-: por la mañana han congelado mi casa y por las noches nos han dormido, a mis hijos y a mí, con gasolina, para saciar en todos nosotros bajas pasiones sexuales.

Durante diez años fui la mujer agredida por alguna persona que me hacía imposible la vida: aún se mete en mi casa para aflojarme los focos en uso, y cambiarme los focos buenos por focos fundidos.

He comprado durante veinte años billetes de lotería, sin ganarlo; buena cosa habría sido que el director de la Lotería Nacional alterara algún día el sorteo, con el único fin de que no perdiese siempre la misma persona (Aguilar 54-55). 
¿Qué otros registros aparecen este año? En Letras Libres, por su parte, "Noticia de los dispersos», de Jorge Fernández Granados (que después lo integrará a su libro Principio de incertidumbre como «Los dispersos»), es un buen ejemplo del espíritu que predomina en la revista:

En una equivocada edad donde caminan

los dispersos los que no han abierto

su verdad al mundo aún al resuello como el hilo

de lo que todos saben y no han dicho

perduran o perseveran en lo limpio los dispersos

en la desigualdad del orden donde guardan

como la sed como la musitante sed su avinagrado día

en ese digno

afán con una cifra

en la orilla de los números del mundo (Fernández Granados 54).

Cercano a David Huerta («Mecanismos del ángel»), Eduardo Hurtado ( $\mathrm{El}$ comensal») y José Luis Rivas («Una sola Helena») está Fernández Granados con la propuesta de explorar personajes. Por su parte, Xirau («Pequeño tríptico») recuerda en su brevedad a Luis Vicente de Aguinaga. Jorge Esquinca («Antídoto») y Ernesto Lumbreras («Suite para gorrión, espigas de trigo verde y granizo», del cual se hablará más adelante) se vinculan por el alejamiento del verso medido -y también del verso libre-. Finalmente, Jorge Hernández Campos («El reloj de cuco»), Francisco Cervantes ("Ni oído ni hablado»), Fabio Morábito («Poema») y Tedi López Mills («La alberca») presentan experiencias que pasan de lo cotidiano hacia un terreno especulativo.

Durante este periodo, los hechos históricos más sobresalientes que les toca vivir en este corte generacional pasan por la experiencia del terremoto de 1985 (para los que radicaban en las zonas afectadas), del mundial de futbol México 86, de la caída del muro de Berlín, la muerte de Carlos Fuentes, Carlos Monsiváis y José Emilio Pacheco, el trayecto que corre de la centralidad del Centro Mexicano de Escritores (CME) y la Sociedad General de Escritores de México (SOGEM) al Fondo Nacional para la Cultura y las Artes (FONCA) y a la Fundación para las Letras Mexicanas (FLM), de la beca casi única del Centro Mexicano de Escritores a los distintos medios de financiamiento para creadores, todo ello junto al asesinato casi sistemático de mujeres en México, el desmantelamiento de la sustentabilidad del agro mexicano, la incapacidad política para abordar la escasez de agua, el fracaso del sistema económico que ya no sólo se contenta con la mercantilización de productos, sino también de las personas y sus cuerpos, la discusión de marcos legales que permiten el flujo de productos a través de las fronteras por medio de tratados comerciales, pero al mismo tiempo implican el cierre de las mismas al tránsito de personas, el regreso del Partido Revolucionario Institucional (PRI) a la Presidencia y la nueva conformación de cárteles de tráfico de drogas: pasamos de Caro Quintero al Chapo, a los templarios, a los Zetas, a la familia michoacana y un largo etcétera de fracasos gubernamentales y descontento generalizado de la sociedad civil.

Si los xv ańos de Rubí marcan un hito en la viralización de un video en México es porque entre 2001 y 2016 las redes adquieren un papel central en la creación de opinión, así como en la configuración del campo poético. Destaca la encuesta vía correo electrónico de Letras Libres en 2005 sobre el mejor poeta vivo en México, cuyo resultado sitúa a Coral Bracho -única mujer en la nómina- en el décimo lugar a decir de los votantes. Recuérdese que en dicho recuento Alí Chumacero ocupó el tercer lugar, aunque el grueso de su obra se había publicado 50 años antes (además de lo cuestionable que resulte su magisterio estético para los autores nacidos entre 1975 y 1985). No se pase por alto que en los apéndices publicados en El manantial latente ${ }^{5}$, el nayarita sólo aparece en la lista «Poetas mexicanos (o residentes en México) vivos», a diferencia de Coral Bracho, que apareció mencionada en tres listados: «Poemas mexicanos (o residentes en México) vivos» (en octavo sitio), «Poemas o libros escritos por poetas mexicanos (o residentes) vivos» (en noveno sitio), «Poetas de la promoción de 1950-1959» (en primer sitio).

Destaca este hecho no sólo porque evidencia la relevancia que la obra de Coral Bracho tenía para inicios del siglo XXI (si se parte de lo mostrado en $E l$ manantial latente), sino también para hacer ostensible la actitud del público votante (en el caso de Letras Libres).

5. El manantial latente, de Ernesto Lumbreras y Hernán Bravo Varela, es la primera antología del siglo xxi publicada ya no por sellos universitarios o por editoriales independientes o marginales, sino por la institución cultural estatal y que arriesga un posicionamiento en torno a la selección de los autores nacidos entre 1965 y 1980. Es por ello, que su recepción fue especialmente crítica y tuvo como reacción -desde el Círculo de Poesía- la publicación de La luz que va dando nombre. Veinte años de poesía última en México, antología coordinada por Alí Calderón. 
Las afinidades electivas/Las elecciones afectivas ${ }^{6}$ es otro de los parangones más visibles en este corte en lo que respecta a las plataformas digitales. Movimiento animado por Rodrigo Castillo, quien gestionó esta antología no editada en papel, representa el segundo momento de aglutinación de poetas y de crítica sobre los autores jóvenes, después de la antología de Lumbreras y Bravo Varela. Las afinidades electivas/Las elecciones afectivas además de antología sin antologador, o de gestión rizomática -cada autor menciona a los pares que le parecen más relevantes de ser incluidos-, es también blog de crítica (desarticulada y de variada calidad) y, plenamente, un espacio digital que incide en la percepción de la obra y la ideología de los autores, quienes se presentan sin mediación de un antologador.

Diez años después, los poetas que aparecen en Letras Libres y Nexos son claramente los poetas contemporáneos, aquellos que han sido identificados por las antologías como los nacidos a partir de 1965; junto a ellos algunos más de las promociones previas. En este mismo contexto, es necesario realizar una aclaración sobre el debilitamiento del espacio de la poesía en la revista Nexos. Durante los doce números de 2016 apenas publica el poema de Bertoltl Brecht «Leyenda del origen del libro Tao Te King cuando Lao Tse iba camino a la emigración» (en traducción de Ricardo Bada), «Pascua de 1916» de W. B. Yeats (en traducción de Luis Miguel Aguilar), el poemahomenaje «Rubén Darío (1867-1916)», de Luis Miguel Aguilar, y unos poemas rescatados de Luis González de Alba.

Para 2016, con casi cuarenta años de vida, Nexos se ha definido como una publicación especializada en temas de sociología, historia, economía, crónica, ensayo, análisis político, aunque mantiene un mínimo espacio para la poesía y la literatura de creación. Con esa distancia, el campo literario mexicano pierde -sin duda- un espacio de amplia difusión; y aunque si bien no se trata de evaluar las directrices editoriales, sí resulta evidente que la revista opta por publicar traducciones de poetas ya fallecidos y por concentrar en la figura de su exdirector la posibilidad de presentar textos poéticos.

Por su parte Letras Libres ofrece un panorama más amplio por examinar. En sus páginas lo mismo hay en 2016 traducciones que poemas de autores nacionales y extranjeros. El recuento, para el caso de los poetas mexicanos es el siguiente: "Mucho calor",

6. Proyecto gestionado por Rodrigo Castillo y que salió a la luz el 23 de octubre de 2006. de Francisco Hernández; «La poeta laureada», de Xitlalitl Rodríguez; "Síndrome de la cabeza estallada», de León Plascencia Nol; "The Fairy Feller's Master Stroke», de Christian Peña; «Pájaro de doble agüero» y «Una patria», de Eduardo Hurtado; «Doy vueltas en la cama...» y "Para seguir echándote a perder...», de Fabio Morábito; «Lo breve, si bueno, dura por siempre», de Merlina Acevedo; «Poemas», de Julián Herbert; "Cielos de hielo», de Pura López Colomé, «Negación de las puertas», de Luigi Amara; "Noche», de Francisco Segovia; "Carta primera», de Isabel Zapata (quien además reseña Pasarás de moda. 35 poetas jóvenes en español en Letras Libres, octubre de 2016); y «Decirte pan», de Antonio Calera-Grobet. ¿Variedad de propuestas?, sin duda; aunque es visible la mayoría de poetas que sobrepasan los 35 años y el reducido número de mujeres poetas en la revista.

Uno de los poemas de Eduardo Hurtado llama la atención por su título, «Una patria». Por la fecha de publicación y el contexto de los años recientes en el país, quizá alguno de los lectores imagine temas de violencia, militarización, descrédito a las instituciones electorales, pérdida de poder adquisitivo, sequía, etcétera; pero no es así:
La patria de este amor
es un desierto,
un cosmos
que se extiende
hasta morder la orilla
del principio (Hurtado 29).

Estos son los versos finales de un poema amoroso que, sin menoscabo de su factura, articula el espacio del amor como esa tierra a la que se está unido, nada habla de la otra patria -la mexicana- que está en una de sus crisis más agudas. Por supuesto, no es que el poema deba hablar de ello, sólo que por el título parecía el texto de mayor tendencia social de entre los publicados por Letras Libres.

«Poemas» de Herbert, junto al de Morábito: «Para seguir echándote a perder...", son los dos más metatextuales. El de Morábito es una continuidad de los parques que dice:

Para seguir echándote a perder

el día

te mando, amigo, otro poema: este.

No lleva título, verás,

y su argumento es este:

seguir echándote a perder el día. 
Para que busques un título te mando,

amigo, este poema,

echándote a leerlo por ahí.

Para seguir amigos

echados a perder por los poemas,

con título o sin él. Para seguir (Morábito 52).

Mientras que el de Herbert es autoirónico e incisivo; un espejo roto en que el lector advierte fragmentos de la realidad:

los poemas peor de todas

los poemas sombrero de fieltro

los poemas mataviejitas

los poemas ropa sucia

los poemas con DJ VJ CB doble cabina y

tubo de téibol

los poemas herpes

genital

los poemas realismo chistoso

los poemas Hola!

los poemas del Círculo

los poemas del circo

los poemas de Ciro Gómez Leyva

los poemas que escribieron

las mejores mentes de mi generación

destruidas por la brisa (Herbert 49) ${ }^{7}$

El último poema que se comenta es el de Xitlalitl Rodríguez Mendoza, publicado en la edición de

7. El poema de Herbert dialoga muy bien con el de Naomi Replansky, "Quejas elevadas a la encargada, musa de la poesía lírica, por el sindicato internacional de los poetas líricos», publicado en Letras Libres el mismo mes y del cual presento una cita:

5. Promueves a los jóvenes de entre nosotros.

¿Qué más pueden hacer los veteranos?

¿Aprender otro oficio? Si hasta esperas

que esos viejos decrépitos compitan

con la versión más joven de sí mismos.

Exigimos una pensión que dé Seguridad estética

y un pequeño subsidio de Sabiduría

para sobrellevar los males del invierno.

7. Tenemos quejas. Nos quejamos.

Pero nunca nos pondremos en huelga.

Tememos por el cierre de tu fábrica

como tememos nuestra muerte.

Hace tiempo, cuando nos diste empleo,

pensamos que sería de por vida (41). enero de 2016 de Letras Libres; en ese número aparece también otro de Francisco Hernández, lo que hace más evidentes sus diferencias. El poema de la jalisciense es quizá el que mejor pone de manifiesto el cambio que apenas se prefigura en este tipo de revistas. Se trata de un texto escrito por una mujer, joven, cuyo título es autoreferencial; "La poeta laureada", pero que escapa al mero procedimiento retórico. El poema presenta un vivo retrato de tres mundos: el del texto escrito, el de la escritora premiada y el de un México, cuyo sistema tributario, electoral y cultural no escapan a la violencia y al absurdo.

Lo transcribo completo no sólo porque es ejemplo de un filón de poesía que no suele aparecer en los grandes espacios de las revistas de este corte, sino porque es uno de los mejores que se han publicado en fechas recientes en México:

Los impuestos pocas veces

son luminosos

pero cuando lo son

llegan en forma de

urnas

boletas

aviones

y hospedaje gratis

flores envueltas

en papel celofán

con nombres como Laura

Palmer o laurel

y no son para todos

En febrero fui a Tixtla

a recoger un premio

y era un impuesto luminoso

en un lugar luminoso

con luminosas

madres sin sus hijos

luminosos

porque a veces

casi siempre

los impuestos

son oscuros

y pesados

y compran armas

negras

oficiales

o desaparecen

se evaporan

no

se transforman

en 
bancos
yates
islas
casas blancas
(con luz negra)
lejanos trucos de magia
o en granaderos
antimotines
y en cápsulas
burbujas
o algo así le llaman
a los golpes
civiles sangrantes
y descalabrados
por sus impuestos
hasta morir
El caso es que un día
fui a Tixtla a
recibir mi ramo
de impuestos
y en un muro
luminoso, había
un pequeño
esténcil que ponía
«Votar mata» (Rodríguez Mendoza 44-45).

En dos años, este par de revistas evidencia -aún en lo limitado del presente acercamiento a su rica historiauna variedad de los discursos poéticos recientes. Que Nexos o Letras Libres dediquen escuetas páginas a la poesía no espanta, pues también se comprueba que ambas la han mantenido pese a los cambios en el mercado impreso y en el sistema cultural. Mientras que 2001 fue el año de inicio de un nuevo siglo, optimista para la cultura, así lo demuestra la proyectada "Feria de Letras" que se llevaría a cabo en una de las sucursales de la tienda Liverpool, donde 3000 metros cuadrados serían destinados a la presentación de 36 editoriales (no se olvide que había tomado posesión como Presidente de México Vicente Fox en diciembre de 2000, Sari Bermúdez estaba al frente del Consejo Nacional para la Cultura y las Artes y se había puesto a consulta y debatido el Plan Nacional de Desarrollo 2001-2006). Por su parte en 2016 los grupos de ultraderecha en el Estado de Nuevo León criticaron los libros de texto de primaria porque se hablaba de la reproducción humana y la sexualidad, ése fue también el arranque de la Secretaría de Cultura (17 de diciembre de 2015) y, aunque todos estos hechos parecen dispares, reflejan muy bien las contradicciones del medio cultural en este breve corte temporal.

«Una patria» y «La poeta laureada» representan muy claramente el cambio de época que hay entre un poeta nacido en 1959 y una nacida en 1982. Mientras en el primero el discurso amoroso tiñe a la patria; en el otro, la premiación de un certamen literario no escapa a la realidad más violenta: «Votar mata». En un país en que los dos proyectos editoriales que se han revisado parecen oponerse, se comprueba-cuando menos en este reducido corpus- que desde un principio Nexos se perfiló hacia la poesía de tinte coloquial y confesional, en su veta norteamericana, mientras que en 2001 Letras Libres parece más cercana a un intimismo que parte del yo. Es cierto que en términos generales ambas publican poesía de corte confesional, de un tono semejante, así como aparecen poemas de métrica regular como sonetos, aunque predomina el verso libre y apenas se asoma el poema en prosa. En este contraste temporal se ratifica que la máscara poética es uno de los rasgos más vivos de la poesía mexicana, que en las revistas se publican poemas breves, pero no fragmentos de corte más experimental o de ruptura.

Si por una parte el recorrido por dos publicaciones y el contraste de dos momentos de su historia nos hace ver lo que está más presente, también permite revelar lo que sus páginas no mostraron. No hay poesía en lenguas indígenas y ambas revistas no se destacan por dar apertura a nuevas propuestas estéticas; es escasa la poesía social y política (a pesar de que «la violencia alcanzó a la poesía», en palabras de Juan Carlos Bautista) y sigue siendo menor el número de mujeres que ambas revistas publican.

\section{Bibliografía}

Aguilar, Luis Miguel. «A la Borges: poema de las imposibles recomendaciones». Nexos, 281 (2001): 54-55.

De Aguinaga, Luis Vicente. «Fragmento». Letras Libres, 36 (2001): 48.

Bautista, Juan Carlos. "Narcoviolencia y poesía: la polca del silencio». Julián Herbert, Javier de la Mora y Santiago Matías (compiladores). Escribir poesía en México. México: Bonobos, 2010: 25-37.

Calderón, Alí (dir.). La luz que va dando nombre, Veinte años de la poesía última en México 1965-1985. Selección de Alí Calderón, José Antonio Escobar, Jorge Mendoza y Álvaro Solís. Puebla: Gobierno del Estado de Puebla, 2007. 
Clement, Jennifer. «La poesía es cuero». Nexos, 280 (2001): 81.

Editorial. «Nexos y el Coloquio de invierno. Coloquio de Primavera». Nexos, 173 (1992): 10.

Fernández Granados, Jorge. «Noticia de los dispersos». Letras Libres, 29 (2001): 54.

Flores, Malva. Viaje de Vuelta. Estampas de una revista. México: Fondo de Cultura Económica, 2011.

Herbert, Julián. «Poemas». Letras Libres, 210 (2016): 49.

Hurtado, Eduardo. «Una patria». Letras Libres, 208 (2016): 29.

KRAUZE, Enrique. «Presentación». Letras Libres, 1 (1999): 6.

Lumbreras, Ernesto y Hernán Bravo Varela (sel., pról., notas y apéndices). El manantial latente. México: Consejo Nacional para la Cultura y las Artes, 2002.

Morábito, Fabio. «Para seguir echándote a perder...». Letras Libres, 209 (2016): 52.

Perales, Jaime. Octavio Pazy el circulo de la revista Vuelta. Tesis doctoral, Georgetown University, 2006.

Pizarro, Ana (coord.). La literatura Latinoamericana como proceso. Buenos Aires: Centro Editor de América Latina, 1985.
Pizarro, Ana (coord.). Hacia una historia de la literatura Latinoamericana. México: Fondo de Cultura Económica, 1987.

Pizarro, Ana (ed.). América Latina: palabra, literatura y cultura. Sao Paulo: Memorial de América Latina: Unicamp, 1993-1995.

QUIRARTE, Vicente. «Sin convite a tu fiesta de fantasmas». Nexos, 281 (2001): 18.

Replansky, Naomi. "Quejas elevadas a la encargada, musa de la poesía lírica, por el sindicato internacional de los poetas líricos». Versión del inglés de Jordi Doce. Letras Libres, 210 (2016): s. p.

Rodríguez Mendoza, Xitlalitl. «La poeta laureada». Letras Libres, 205 (2016): 44-45.

STANTON, Anthony. Inventores de tradición: ensayos sobre poesía mexicana moderna. México: Fondo de Cultura Económica, 1998.

Trujillo, Julio. «Contra el sopor». Letras Libres, 30 (2001): 101.

Vidal López-Tormos, Yolanda. «Una aproximación al panorama de las publicaciones periódicas literarias mexicanas (1950-1995)». Anales de Literatura Hispanoamericana, 24 (1995): 259-269.

ZaID, Gabriel. Asamblea de poetas jóvenes de México. México: Siglo xxi, 1980. 